\title{
Eksplorasi Jamur Makroskopis di Hutan Oeluan Kabupaten Timor Tengah Utara
}

Lukas Pardosi $^{\mathrm{a}}$, Florian Mayesty Prima Makin ${ }^{\mathrm{b}}, \mathrm{I}_{\text {Gede Arya Wiguna }}^{\mathrm{c}}$

${ }^{a}$ Fakultas Pertanian, Universitas Timor, Kefamenanu, TTU - NTT, Indonesia, email: lukaspardosi51@unimor.ac.id

${ }^{b}$ Fakultas Pertanian, Universitas Timor, Kefamenanu, TTU - NTT, Indonesia, email: florian@unimor.ac.id

${ }^{c}$ Fakultas Pertanian, Universitas Timor, Kefamenanu, TTU - NTT, Indonesia, email: gede.arya@unimor.ac.id

\section{Article Info}

Article history:

Received 13 Mei 2020

Received in revised form $17 \mathrm{Mei} 2020$

Accepted 25 Mei 2020

DOI

https://doi.org/10.32938/slk.v3i1.1024

Keywords:

Eksplorasi,

Jamur Makroskopis,

Hutan Oeluan

\section{Abstrak}

Penelitian mengenai keanekaragaman jamur makroskopis di kawasan Hutan Oeluan kabupaten Timor tengah Utara Belum pernah

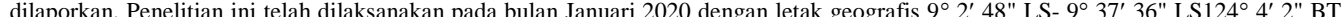
$124^{\circ} 46^{\prime}$ 0" BT, penelitian ini dilakukan pada empat jalur yang berbeda. Panjang jalur pengamatan adalah 100 m. Metode yang dilakuan pada setiap Jalur pemgamatan di setiap adalah metode jelajah dan Purpossive sampling, berdasarkan keberadaan jamur makroskopis yang dianggap mewakili kawasan tersebut, setelah itu dilanjutkan dengan mencatat jumlah individu, koleksi dan dokumentasi. Pengamatan dan pengkoleksian spesies dilakukan secara eksploratif. Dari hasil penelitian ditemukan 9 spesies jamur makroskopis yaitu, Ganoderma aplatum, Earliella scabrosa, Polyporus tenuiculus, Polyporus squamosus, Mikroporus xanthopus, Favolus grammocephalus, Pycnoporus cinnabarinus, Ganoderma lucidium, Laccaria vinaceoavellaneae.

\section{Pendahuluan}

Hutan oeluan merupakan salah satu cagar alam yang terletak di kabupaten Timur Tengah Utara, provinsi Nusa Tenggara Timur. Hutan Oeluan selain menjadi objek wisata juga berfungsi sebagai cagar alam. Hutan oeluan merupakan cagar alam yang menyimpan banyak biodiversitas. Salah satu biodiversitasnya adalah jamur. Jamur merupakan salah satu organisme yang memegang peranan penting dalam kehidupan, peranan dari jamur adalah menguraikan bahan organik yang kompleks yang ada di alam menjadi satu unsur yang lebih sederhana, sehingga hsil penguraian dapat dimanfaatkan oleh organisme lain.

Keberadaan jamur di seluruh dunia diperkirakan jumlahnya dapat mencapai 1,5 juta spesies yang diprediksi masih hidup jumlah jamur teridentifikasi sampai saat ini baru mencapai sekitar 100.000 spesies (Campbell dkk, 2012) yang artinya bahwa masih banyak jumlah spesies jamur yang belum teridentifikasi. Jamur memperoleh makanan atau sumber nutrisi dengan menggunakan suatu alat yang terdiri dari benang-benang halus yang disebut dengan hifa (Anggriawan, 2014). Jamur merupakan organisme eukaryotik, berspora, tidak berklorofil, bereproduksi secara seksual dan aseksual, jamur berdasarkan ukuran tubuhnya ada yang makroskopis yaitu jamur yang berukuran besar, sehingga dapat dilihat dengan mata telanjang dan ada juga jamur yang mikroskopis yaitu jamur yang berukuran kecil dan hanya dapat dilihat dengan menggunakan alat bantu mikroskop (Darwis, 2011).

Tampubolon (2010) menyatakan jamur khususnya kelompok jamur makroskopik atau makrofungi (Basidiomycota), merupakan kelompok utama organisme pendegradasi lignoselulosa karena mampu menghasilkan enzimenzim pendegradasi lignoselulosa seperti selulase, ligninase, dan hemiselulase, sehingga daur materi di alam dapat terus berlangsung.

Identifikasi jamur selain sebagai sumber dan bahan informasi tentang jumlah spesies jamur, juga termasuk dalam salah satu hal terpenting dari delapan poin yang dimasukan dalam deklarasi milenium atau kesepakatan milenium dari seluruh kepala negara anggota PBB yang dilangsungkan di New York, Amerika Serikat tahun 2008 serta dengan lembagalembaga internasional lainnya, deklarasi tersebut dikenal dengan istilah Millenium Development Goals. Salah satu isi dari deklarasi tersebut adalah kelestarian lingkungan dengan mengurangi atau mengantisipasi laju berkurangnya keanekaragaman hayati (Stalker, 2008).

Proborini (2006) menyatakan bahwa identifikasi jamur makroskopik berarti identifikasi yang dilakukan dengan cara pengamatan morfologi secara makroskopik. Parameter yang digunakan sebagai acuan untuk mengamati jamur meliputi ciri makroskopik (bentuk, warna dan tekstur tubuh buah, kehadiran cincin dan volva, serta bentuk akrosphora).

2. Metode

Penelitian ini dilaksanakan di kawasan hutan Oeluan, Desa Bijeli, Kecamatan Noemuti Kabupaten Timor Tengah Utara (TTU), Provinsi Nusa Tenggara Timur. Metode penelitian yang dilakukan adalah metode Purpossive sampling, berdasarkan keberadaan jamur makroskopis yang dianggap mewakili kawasan tersebut, setelah itu dilanjutkan dengan mencatat jumlah individu, koleksi dan dokumentasi. Penjelajahan dilakukan pada setiap plot, dan arah jelajahnya disesuaikan dengan arah transeknya. Jamur yang ditemukan di setiap plot dikoleksi dan diambil setiap jenis untuk diidentifikasi lebih lanjut menggunakan buku kunci determinasi dan buku jamur Jepang (Imazeki dkk., 1988).

3. Hasil dan Pembahasan

Hutan cagar alam oeluaan secara geografis terletak di kawasan $9^{\circ} 2^{\prime} 48^{\prime \prime}$ LS- $9^{\circ}$ 37' 36" LS124 4' 2" BT- 12446' 0" BT,dari hasil jelajah ditemukan beberapa spesies jamur basidyomicota di hutan oeluan seperti pada tabel 1 berikut ini.
Tabel.1 Hasil Eksplorasi Jamur Makroskopis Hutan Oeluan

\begin{tabular}{ccc}
\hline No & Nama Spesies & Jumlah \\
\hline 1 & Ganoderma applanatum & 57 \\
2 & Tyromyces sambuceus & 2 \\
3 & Polyporus tenuiculus & 5 \\
4 & Polyporus squamosus & 1 \\
5 & Mikroporus xanthopus & 7 \\
6 & Favolus grammocephalus & 1 \\
7 & Pycnoporus cinnabarinus & 1 \\
8 & Ganoderma lucidium & 7 \\
9 & Laccaria vinaceoavellaneae & 2 \\
\hline
\end{tabular}

Solle (2017) menyatakan diversitas sangat tergantung pada kemerataan individu antar spesies dan bukan semata-mata pada kekayaan spesiesnya sehingga yang menyebabkan naiknya nilai indeks. Diversitas adalah kemerataan antarspesies. Jika selisih semakin besar, maka kemerataan semakin berkurang, sebaliknya jika selisih jumlah individu antarspesies semakin kecil, maka kemerataan semakin tinggi. Kemerataan semakin maksimum bila semua spesies mempunyai individu yang sama sehingga terjadilah keanekaragaman spesies.

\subsection{Ganoderma aplatum}

Pusat penelitian Indonesia (LIPI) pada tahun 2017 menyatakan Ganoderma applanatum merupakan kelompok jamur yang termasuk famili polyporaceae.memiliki tubuh buah berupa kipas,himenofora merupakan buluh buluh (pori) yang dilihat dari luar berupa lubang.Lubang sisi dalam lubang lubang itu dilapisi himenium.Sebagian hidup sebagai saprofit.Tubuh buah berbentuk setengah lingkara,banyak terdapat pada kayu - kayu yang telah lapuk. Ganoderma applanatum termasuk dalam ordo hymenomycetales yang secara umum mempunyai ciri-ciri:

- Basidium terkumpul merupakan himenium

- Jika himenium sudah masak,kebnyakan terletak bebas diatas tubuh buah (gimnokarp)

- Spora luar biasanya berguna banyak dan secara aktif dilemparkan oleh basidium.

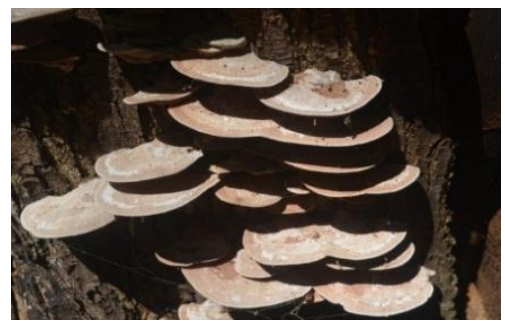

Gambar 1. Ganoderma Aplatum

\subsection{Earliella scabrosa}

Habitat Earliella scabrosa terdapat pada kayu mati Persebaran: umum di daerah tropis dan subtropis terutama di tempat terbuka dan hutan yang telah terdegradasi. Earliella scabrosa memiliki ciri khas tubuh buah berwarna merah marun, kadang memiliki zonasi, pertama putih hingga krem kemudian ditutupi oleh kutikula berwarna merah marun mulai dari pangkal tudung, pada spesimen tua warna merah menutupi seluruh permukaan tudung, ketika kering kutikula sedikit mengerut. Permukaan pori putih, pori berliuk hingga semidaedaloid (LIPI, 2017). 


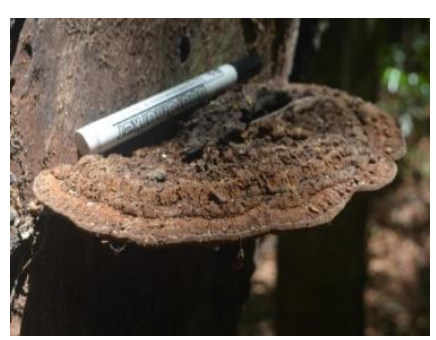

Gambar 2. Earliella scabrosa

\subsection{Polyporus tenuiculus}

Jamur dari familia Polyporaceae ini memiliki ciri - ciri pada umumnya berbentuk Classis. Menurut Tjitrosoepomo (2009), jamur dari familia Polyporaceae memiliki tubuh buah yang besar berupa kipas yang dapat berumur beberapa tahun dan berstruktur keras berkayu sehingga familia ini memiliki kemampuan adaptasi yang baik diberbagai tempat pada ketinggian yang berbeda dengan kelembapan yang tinggi. Jamur ini juga membentuk himenofora atau buluh - buluh (pori) yang dilihat dari luar berupa lubang - lubang.

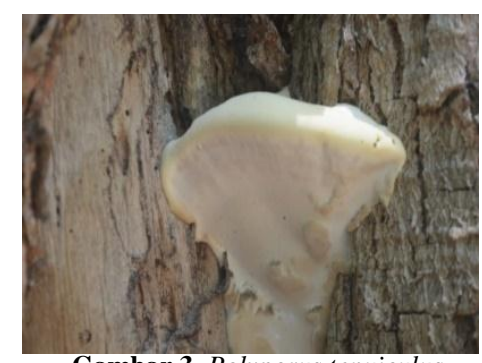

Gambar 3. Polyporus tenuiculus

\subsection{Polyporus squamosus}

Spesies jamur Pleurotus pulmorius hidup yang berkelompok atau berklaster pada kayu yang sudah mati, ternaungi oleh pepohonan, memiliki suhu yang dingin yaitu sekitar $6^{\circ} \mathrm{C}$ hingga $22^{\circ} \mathrm{C}$. Spesies jamur ini dapat dibedakan dengan spesies lain dengan melihat morfologisnya berwarna putih, tidak bertangkai, memiliki lamela atau gills yang berwarna putih, tumbuh di daerah lembab, dan bagian bawah basidiokarpnya berwarna putih, tudung atau basidiokarpnya berbentuk setengah lingkaran mirip dengan cangkang pada tiram dengan bagian tengah agak cekung. Adapun penampakan morfologi jenis-jenis jamur yang ditemukan di hutan oeluan dapat dilihat pada gambar 4 (LIPI, 2017).

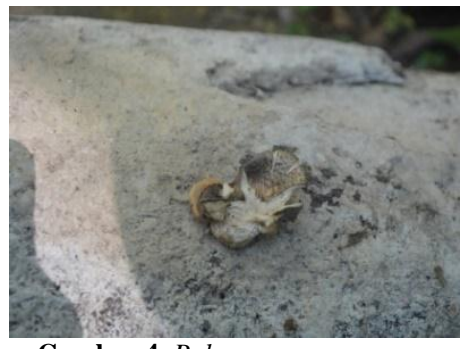

Gambar 4. Polyporus squamosus

\subsection{Mikroporus Xanthopus}

Habitat: pada kayu mati Persebaran: sangat umum di daerah tropis di Afrika, Eropa dan Asia. M xanthopus memiliki tubuh buah berbentuk corong, dengan tangkai berada di tengah. Tudung berdiameter antara 3-6 cm, gundul dan mengkilap ketika segar tetapi menjadi kusam saat kering, berwarna cokelat kekuningan hingga cokelat kemerahan, dengan banyak zona konsentris, dengan berseling warna gelap dan terang, tepi bergelombang. Tangkai bulat, gundul, ditutupi dengan kutikula tipis berwarna cokelat muda kekuningan, dengan panjang hingga $6 \mathrm{~cm}$, tangkai sedikit semakin ke atas semakin membesar, begitu pula pada bagian pangkal. Permukaan pori berwarna krem hingga putih. Pori rata dan sangat kecil, hampir tidak dapat terlihat dengan mata telanjang, $8-10 / \mathrm{mm}$ (LIPI, 2017).

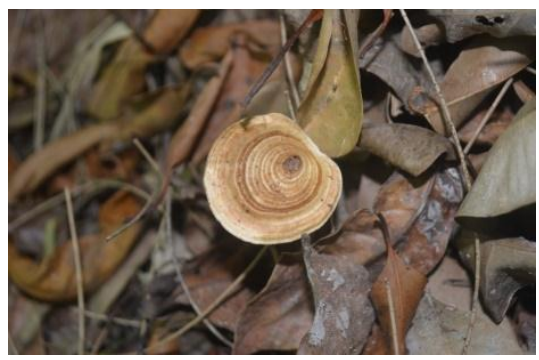

\subsection{Favolus grammocephalus}

Habitat Favolus grammocephalus pada kayu mati. Persebarannya endemik Asia dan Australia, mulai dari Pakistan hingga China dan Fiji. Jamur ini memiliki tubuh buah mengipas atau menyudip, melekat lateral dengan tangkai yg menyerupai pangkal yang mengerut, berwarna kuning kecokelatan hingga cokelat atau cokelat muda. Tidak memiliki tangkai sejati. Permukaan pori cokelat muda (LIPI, 2017).

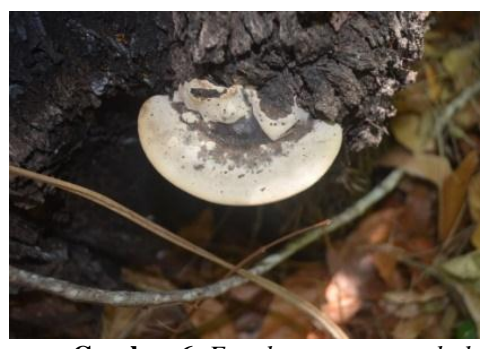

Gambar 6. Favolus grammocephalus

\subsection{Pycnoporus cinnabarinus}

Habitat Pycnoporus cinnabarinus pada kayu mati di daerah terbuka dan terkena sinar matahari. Jamur ini mudah ditemukan di daerah yang telah terbuka pada potongan batang kayu yang banyak terkena sinar matahari. Jamur ini memiliki ciri khas tudungnya yang berwarna jingga cukup mencolok dari jamur-jamur lain (LIPI, 2017).

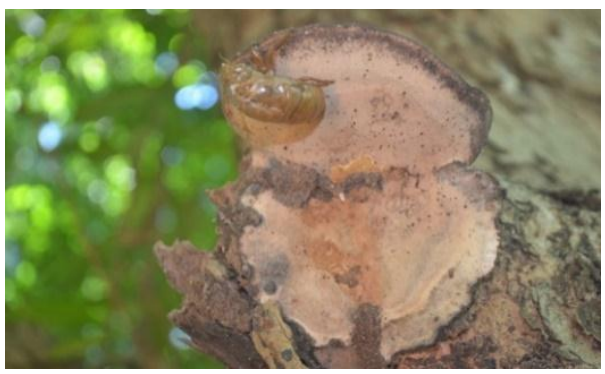

Gambar 7. Pycnoporus cinnabarinus

\subsection{Ganoderma lucidium}

Jamur Ganoderma lucidum merupakan spesies dari Ordo Polyporales dan familia Polyporaceae yang lebih dikenal dengan sebutan jamur Reishi atau Lingzi. Jamur ini berbentuk setengah lingkaran dan berwarna merah kecoklatan. Bagian permukaan atas halus dan mengkilap sedangkan bagian bawah terdapat pori-pori, jamur ini memiliki tangkai yang berwarna seperti tudungnya Jamur Ganoderma lucidum merupakan spesies dari Ordo Polyporales dan familia Polyporaceae yang lebih dikenal dengan sebutan jamur Reishi atau Lingzi. Jamur ini berbentuk setengah lingkaran dan berwarna merah kecoklatan. Bagian permukaan atas halus dan mengkilap sedangkan bagian bawah terdapat pori-pori, jamur ini memiliki tangkai yang berwarna seperti tudungnya (LIPI, 2017).

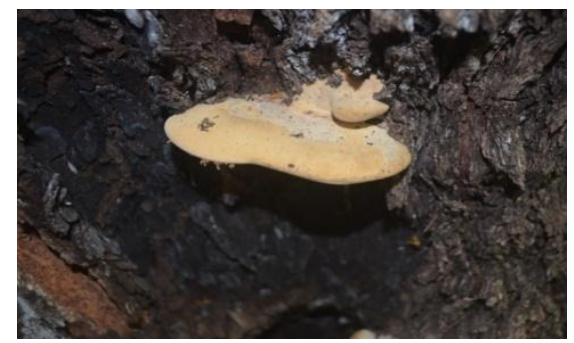

Gambar 8. Ganoderma lucidium

\subsection{Lycoperdaceae sp}

Jamur golongan ini merupankan jamur yang sering tumbuh diatas tanah. Jamur ini tumbuh dibantu oleh angin. Spora akan keluar jika jamur disentuh

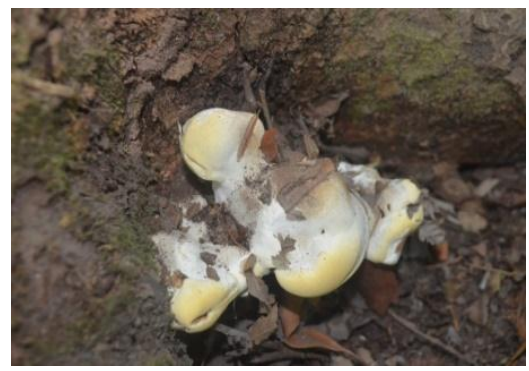

Gambar 9. Lycoperdaceae sp 


\section{Simpulan}

Jamur makro yang terdapat di dalam kawasan cagar alam Hutan oelan yaitu berjumlah 7 spesies, yaitu Ganoderma aplatum, Earliella scabrosa, Polyporus tenuiculus, Polyporus squamosus, Mikroporus xanthopus, Favolus grammocephalus, Pycnoporus cinnabarinus, Ganoderma lucidium, Laccaria vinaceoavellaneae

\section{Pustaka}

Anggriawan, I 2014. Inventarisasi Jamur Tingkat Tinggi (Basidiomycetes) Di Gunung Singgalang Sumatera Barat. Jurnal Biologi Universitas Andalas (J. Bio. UA.) 3(2)-Juni 2014 : 147-153 .ISSN : 2303-2162.

Campbell, Reece, Urry, Cain, Wasserman, Minorsky dan Jackson 2012. Biologi Edisi Kedelapan Jilid 2. Erlannga: Jakarta.

Darwis, W 2011. Inventarisasi Jamur Yang Dapat Dikonsumsi Dan Beracun Yang Terdapat Di Hutan Dan Sekitar Desa Tanjung Kemuning Kaur Bengkulu. Konservasi Hayati, 7 (2). pp. 1-8. ISSN 0216-9487.

Imazeki, R., Otani, Y. dan Hongo, T. 1988. Fungi Of Japan. YAMA-KEI Publishers.co ltd, 1-3-33, Shiba - Daimon, Minato-ku, Tokyo - Japan.

Lembaga ilmu pengetahuan Indonesia (LIPI). 2017. Berita Biologi. Jurnal Ilmu Hayati, Volume 16 Nomor 3.

Proborini, W. M. 2006. Eksplorasi Dan Identifikasi Jenis-Jenis Jamur Klas Basidiomycetes Di Kawasan Bukit Jimbaran Bali. Jurnal Biologi, XVI(2): $45-47$.

Solle, H., Klau, F., Nuhamara, S. T. 2017. Keanekaragaman Jamur di Cagar Alam Gunung Mutis Kabupaten Timor Tengah Utara, Nusa Tenggara Timur. Biota Vol. 2 (3): 105-110

Stalker, P. 2008. Millennium Development Goals Cetakan Kedua. Laporan BAPPENAS dan UNDP.

Tampubolon, J. 2010. Inventarisasi Jamur Makroskopis Di Kawasan Ekowisata Bukit Lawang Kabupaten Langkat Sumatera Utara. Tesis: USU.

Tjitrosoepomo, G. 2009. Taksonomi Tumbuhan. Gajah Mada. Yogyakarta: University Press. 